\title{
CRACK STABILITY IN THE FRACTURE OF CEMENTITIOUS MATERIALS
}

\author{
S. Tandon ${ }^{*}$, K.T. Faber ${ }^{*}$ and Z.P. Bazant ${ }^{* *}$, \\ ${ }^{*}$ Dept. of Materials Science and Engineering, \\ ${ }^{* *}$ Dept. of Civil Engineering, \\ Robert R. McCormick School of Engineering and Applied Science, \\ Northwestern University, Evanston, Il 60208.
}

\begin{abstract}
The aim of the present study is to investigate the stability of crack propagation in cementitious materials. Tests were conducted on bend specimens in three-point and four-point loading conditions. Three-point bend specimens showed stable crack growth for mortar, normal strength and high strength concrete specimens. Alternatively, four-point bend specimens showed catastrophic failure for mortar and quasi-catastrophic failure for normal strength and high strength concrete specimens. Results will be discussed in relation to brittleness number model and specific microstructural features including the interfacial transition zone between the cement paste and the aggregate and the attendant toughening mechanisms.
\end{abstract}

\section{INTRODUCTION}

The measurement of fracture toughness and resistance-curve (or R-curve) behavior in brittle and quasi-brittle materials often requires the stable growth of a single crack through the specimen. The assurance of crack stability is of particular interest in the study of cementitious materials, such as cement paste, mortar and concrete, where process zone shielding has been documented to give rise to R-curve behavior [1-3]. Specifically, the process zone phenomena in these materials include crack bridging by unhydrated cement grains in cement paste [4], crack bridging by aggregates [5] and microcracking [6] in concrete.

A number of issues influencing crack stability during fracture tests have been investigated already. For example, theoretical models have been developed to predict the stability of shrinkage cracks in concrete and reinforced concrete [7]. Geometric factors, such as notch depth in notched-beam specimens [8] and specimen size [9,10] have been explored both experimentally and analytically. In geometrically similar specimens, large samples tend to fail catastrophically while small specimens show stable crack growth $[9,10]$. Long starter notches improve the stability of crack extension in notched-beam tests [8]. One interesting well-established property is that crack extension during three-point bend tests is inherently more stable than four-point bending [11]. What is not well understood are the microstructural changes, particularly in process zone phenomena, that differ under the two loading conditions. The intent of this work is to examine, firstly, crack stability in three- and four-point bend testing of mortar, normal strength and high strength concrete, and, secondly and more importantly, the differences in the microstructural aspects of fracture which accompany the change in loading.

\section{EXPERIMENTAL DETAILS}

The materials used for this study- mortar, normal strength concrete (NSC) and high strength concrete (HSC)-were designed and mixed in the laboratory. The mix ratio (by weight) of the normal strength concrete, was cement: sand: gravel: water $=1: 2: 2: 0.6$. The mix ratio of the high strength concrete, by weight, was cement: sand: gravel: water: silica fume $=1: 2: 2: 0.3: 0.3$. A 
water reducing agent ${ }^{*}(88.5 \mathrm{ml})$ was added to one batch $\left(\sim 0.3 \mathrm{ft}^{3}\right)$ of the high strength concrete mix. Silica fume ${ }^{f}$ was used as a mineral admixture to strengthen the interface between the aggregate particles and the matrix. The mix ratio (by weight) of the mortar, was cement: sand: water $=$ 1: 2: 0.6. Type I portland cement, P (pea-) type gravel and ASTM \# 2 sand were used. The maximum aggregate size in the mixes of normal and high strength concrete was $9.5 \mathrm{~mm}$.

Single-edge notched beams were cast, with beam depth, $d=76 \mathrm{~mm}$. For all the beam specimens, the length-to-depth ratio was equal to $8 / 3$, the ratio of notch length, $a_{o}$, to depth was $1 / 3$, and specimen thickness was $38 \mathrm{~mm}$. All the specimens were compacted by rodding and vibration. The specimens were left in the molds during the first $24 \mathrm{~h}$ and were removed and cured in water until the time of testing. The notches were cut with a diamond band saw and were 1.8 $\mathrm{mm}$ wide. Companion cylinders of $76 \mathrm{~mm}$ diameter and $152 \mathrm{~mm}$ length were cast. These cylinders were capped with a sulphur compound and cured under water with the notched specimens. The cylinders were tested in compression after 28 days of curing. Normal strength concrete cylinders failed at an average maximum compressive strength of $46.4 \mathrm{MPa}$, with a standard deviation of 5.4 percent. High strength concrete cylinders had an average compressive strength of 73.2 $\mathrm{MPa}$, with a standard deviation of 3.3 percent.

Bend specimens were loaded on a servo-electric mechanical testing machine ${ }^{*}$ at a constant crosshead displacement rate of $2 \mu \mathrm{m} / \mathrm{min}$. During each test, the load, crosshead displacement and crack mouth opening displacement (CMOD) were monitored at $1 \mathrm{~Hz}$ with a data acquisition system. ${ }^{* *}$ The crack opening displacement was measured using a clip gage. ${ }^{\dagger \dagger}$ For the three-point bend tests, the outer span, $l_{o}$, was $188 \mathrm{~mm}$ whereas for the four-point bend tests, the outer span was $188 \mathrm{~mm}$ and the inner span, $l_{i}$, was $94 \mathrm{~mm}$. Four to ten specimens were tested for each loading condition (three- or four-point bend test), for each material.

A camera was attached to a traveling microscope mounted on the base of the testing machine. At the end of the test, the motion of the crosshead was arrested and crack pictures were taken. The specimen was unloaded and its surfaces were examined under an optical microscope for evidence of any side cracking or any other difference in the crack profiles on the front (surface facing the camera) and back surfaces.

\section{RESULTS}

Figure 1(a) shows the load versus CMOD plot of a normal strength concrete specimen tested in three-point bending. Crack growth in this specimen is stable in contrast to normal strength concrete specimen tested in four-point bending (Figure 1(b)). In this experiment a sudden load drop occurs in the softening branch of the load-CMOD curve and the crack opens by a few hundred microns followed by a stable crack growth with a slowly decreasing load carrying capacity. To explore the effect of the inner span on the stability of the test, the inner span was reduced to 15 $\mathrm{mm}$ (the allowable minimum inner span roller distance on the fixture). The load-CMOD plot of this test is shown in Figure 1(c). Stability of the crack growth is improved over the four-point bend test with the wide inner span.

\footnotetext{
* W.R.Grace, Daracern-100, Cambridge, MA

$\dagger$ W.R.Grace, WRDA-19, Cambridge, MA

$\ddagger_{\text {MTS } 808 \text {, Materials Testing Systems, Minneapolis, MN }}$

** Macintosh SE computer with an Analog Connection SE data acquisition card

${ }^{\dagger \dagger}$ MTS, COD GAGE 632.03E-30, Minneapolis, MN
} 

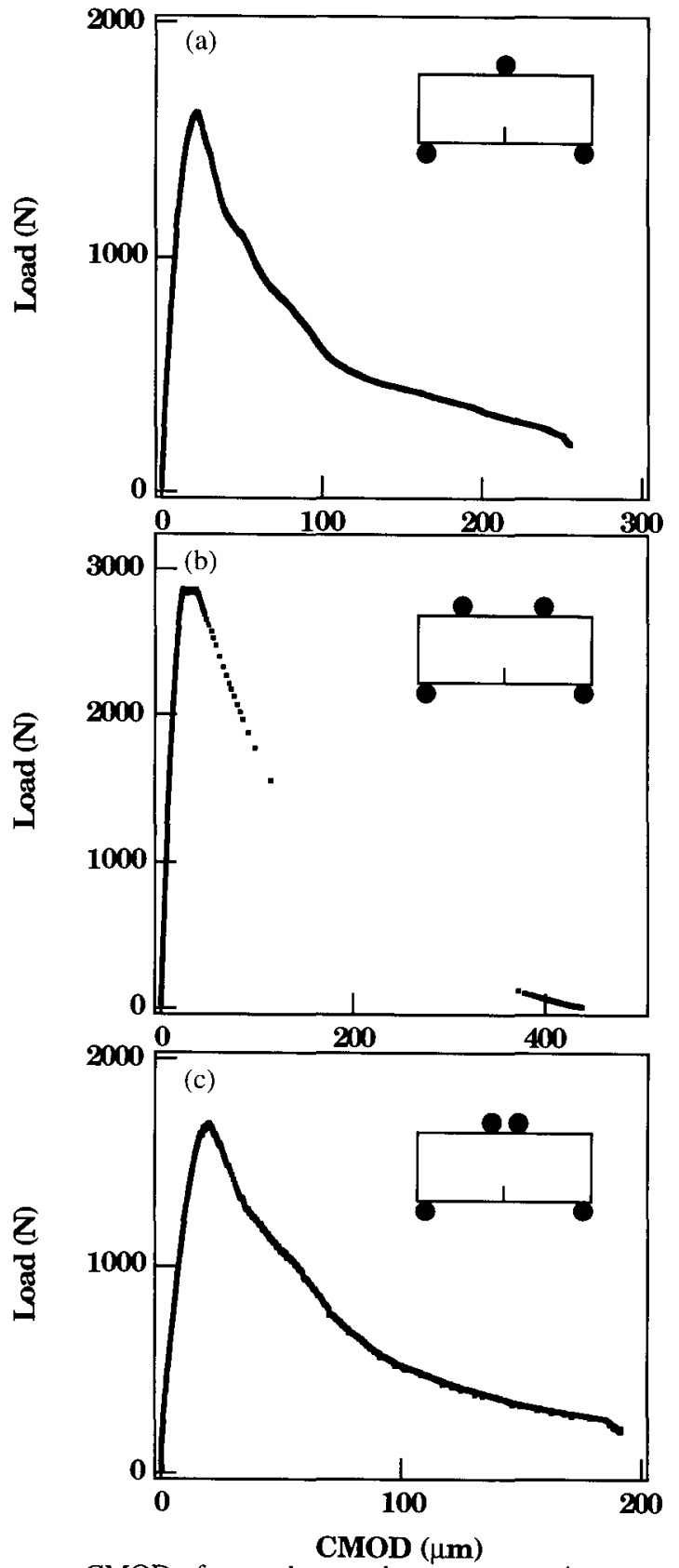

Figure 1: Load versus CMOD of normal strength concrete specimens tested in (a) three-point bending (b) four-point bending and (c) four-point bending with reduced inner span. 
Similar results are demonstrated in high strength concrete (Figure 2), however, in fourpoint bending the extent of instability is larger than for normal strength concrete with crack opening of nearly $500 \mu \mathrm{m}$ prior to crack arrest. In mortar, crack arrest never occurs in four-point bending, as seen in Figure 3(b). In contrast, three-point bending results in stable crack extension in mortar (Figure 3(a)).

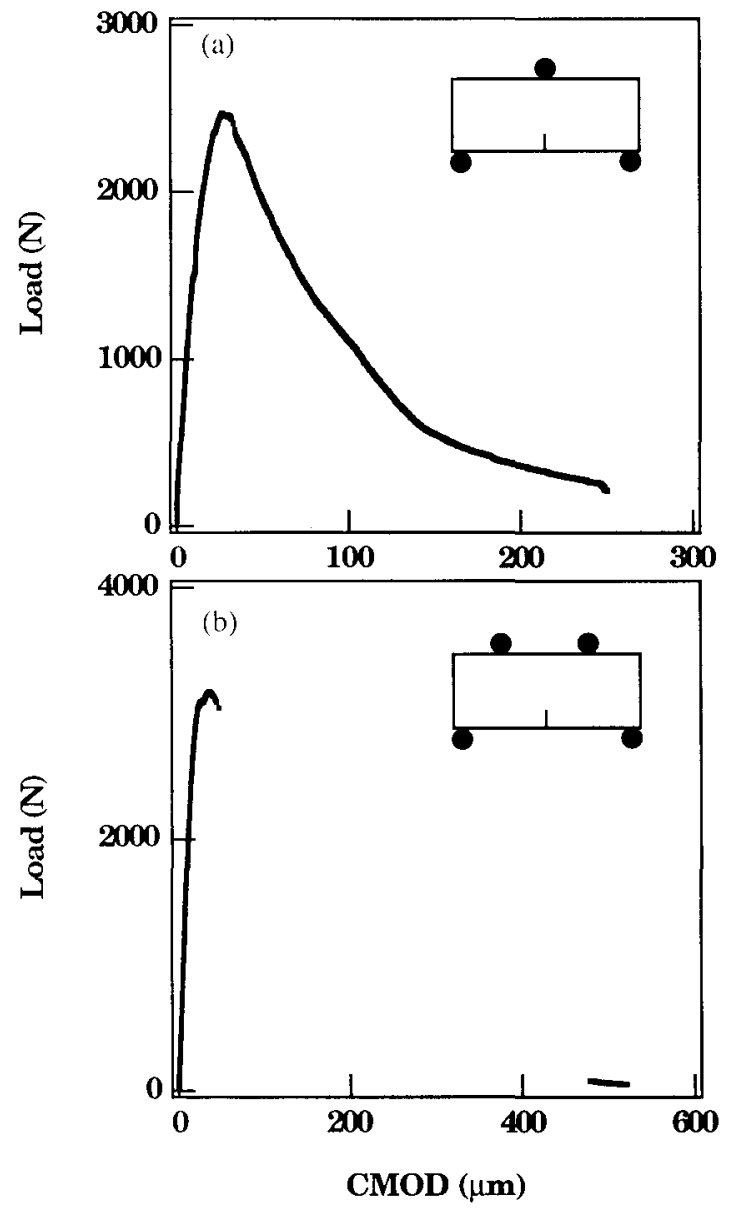

Figure 2: Load versus CMOD of high strength concrete specimens tested in (a) three-point bending and (b) four-point bending.

Figure 4 shows a fully developed crack profile in normal strength concrete recorded at the end of the four-point bend test prior to unloading the specimen. Different sites marked A to E show various microfracture toughening mechanisms active in the material. All these sites are shown in the insert at a higher magnification. Point $\mathrm{A}$ shows offset crack being bridged by the untorn ligaments in the materials. Grain localized bridging is evident at point B. Point $\mathrm{C}$ shows an example of the debris wedging, likely a deflection and localized branching of the main crack 


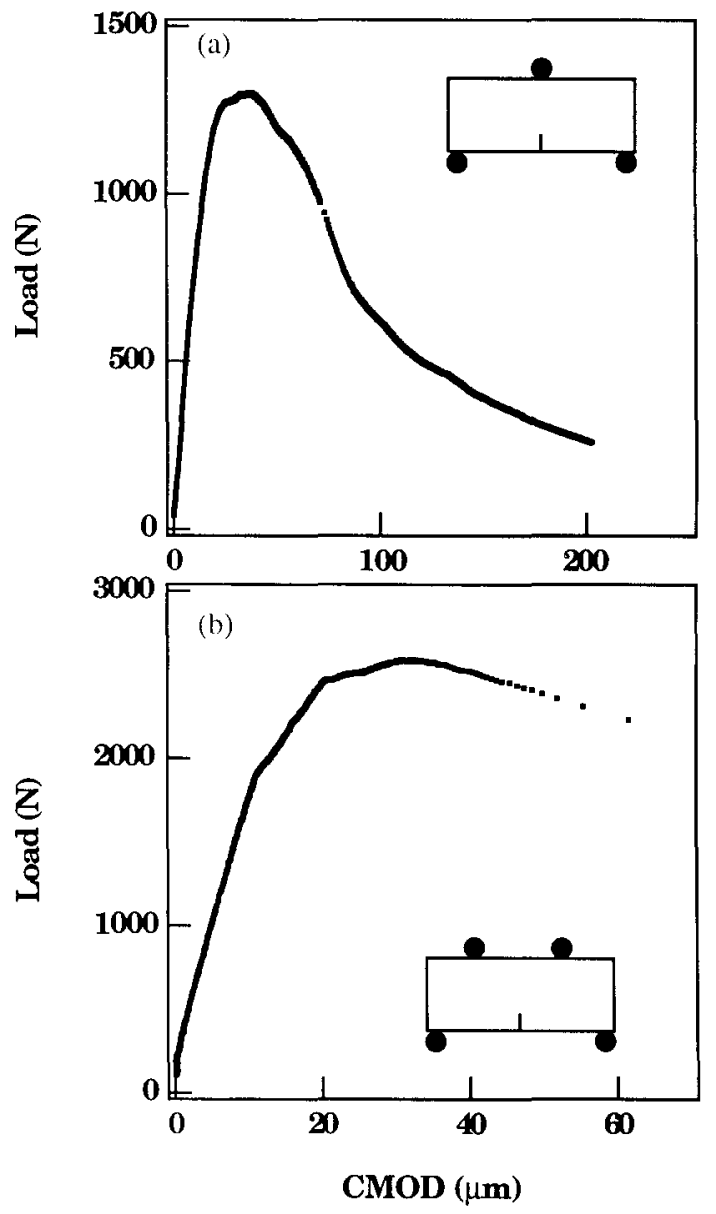

Figure 3: Load versus CMOD of mortar specimens tested in (a) three-point bending and (b) four-point bending.

are illustrated in area D. Furthermore, these cementitious materials have a "damage zone" of the discontinuous cracks at the end of the main crack. Area E shows the "damage zone" observed in the specimen. Similar toughening mechanisms are active in the specimens tested in three-point bending.

Optical micrographs were taken of the crack profiles on the front and back surfaces of the tested specimens. As shown in the Figure 5(a), on the back surface of the normal strength concrete specimen tested in the four-point bending, a crack parallel to the main crack is seen at a distance of 4-5 mm from the main crack and extends over a length of approximately $20 \mathrm{~mm}$. This second crack is not seen on the front surface so it does not extend through the whole thickness of the specimen. A similar big mass of the concrete between the two cracks was seen in the fourpoint bend specimen tested with reduced distance $(15 \mathrm{~mm}$ ) between the upper rollers (Figure 


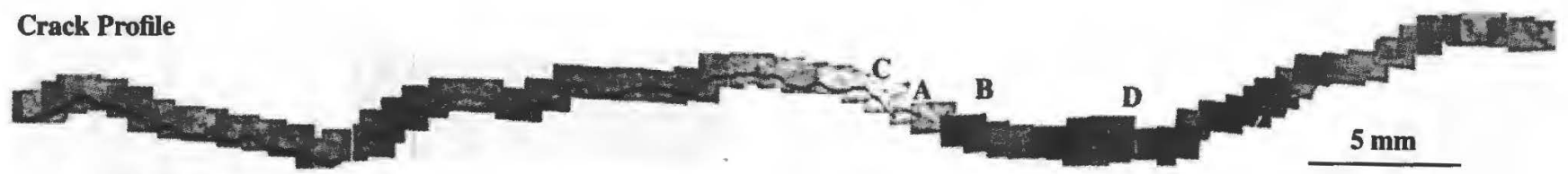

Toughening mechanisms

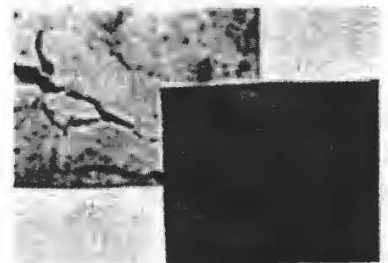

A

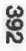

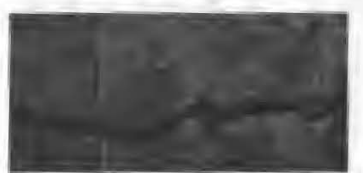

B

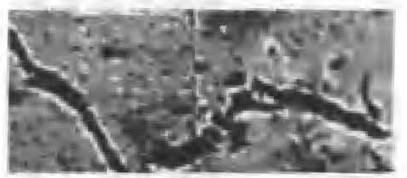

C

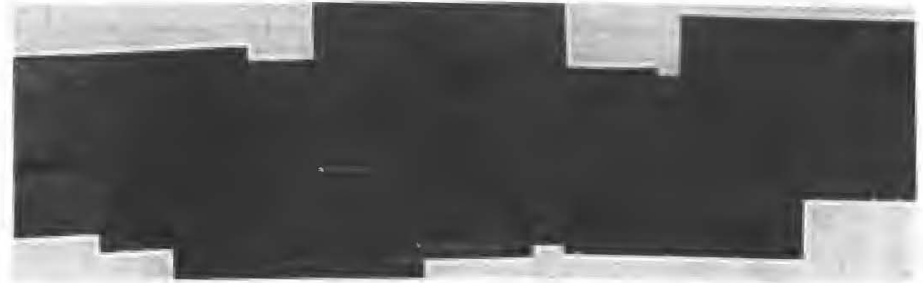

D

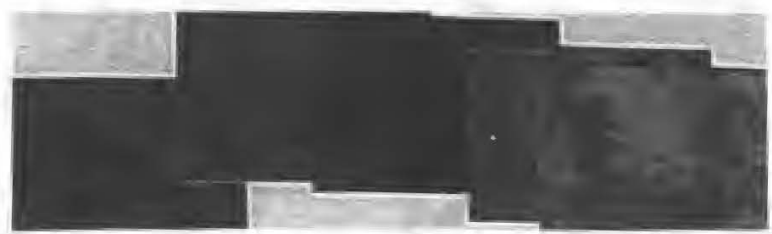

$\mathbf{E}$

$1 \mathrm{~mm}$

Figure 4: Crack profile of a normal strength concrete specimen recorded at the end of the four point bend test. Inserts A-E show toughening mechanisms active in the material at a higher magnification. A-Untorm ligaments, B-Grain bridging, C-Debris wedging, D-Deflection and localized branching and E-Damage zone. 


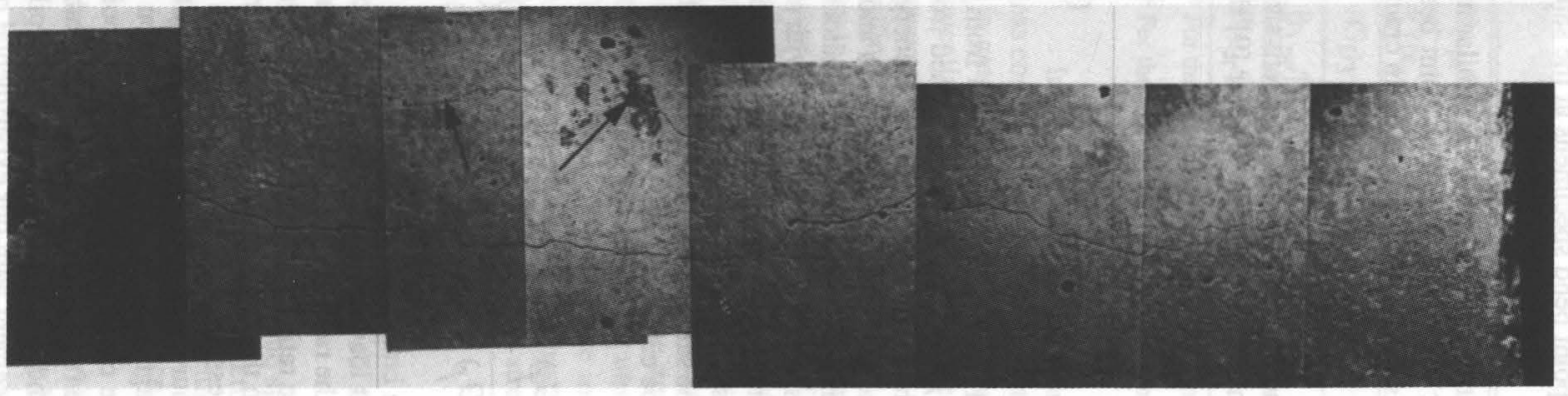

(a)

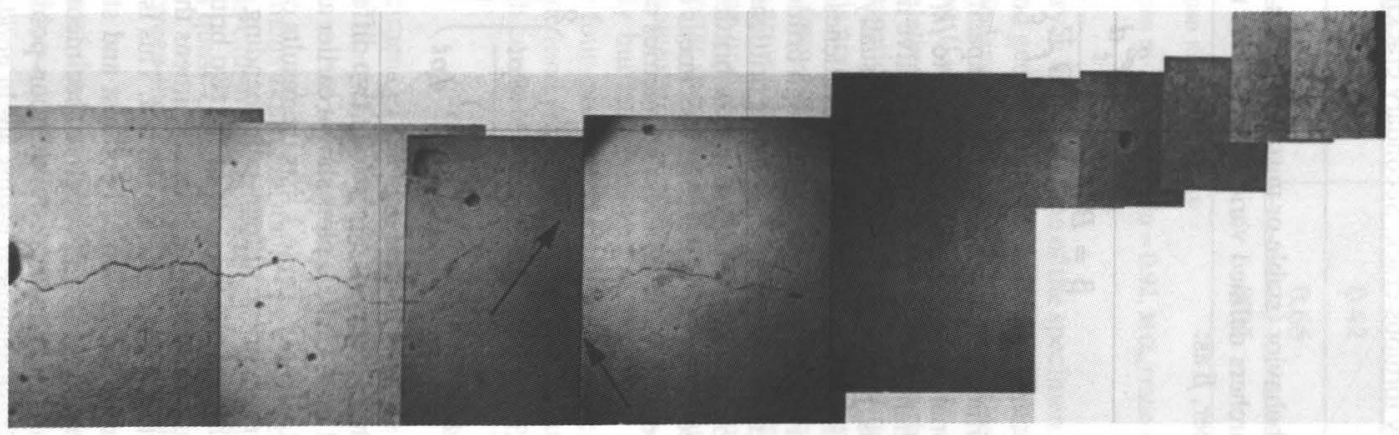

(b)

$10 \mathrm{~mm}$

Figure 5: Optical micrographs of the back surface of the normal strength concrete specimen tested in (a) four-point bending and (b) fourpoint bending with reduced inner span. Arrows point to secondary cracks on the surface. 
5(b)). No such parallel cracks were seen on either surface of the specimens tested in three-point bending. At higher magnification, several disconnected cracks were found in the specimens loaded in four-point bending. No such cracks were seen in three-point bend specimens at the same magnification.

Analysis of the pictures taken prior to unloading high strength concrete show similar microfracture processes as seen in the normal strength concrete specimens. The four-point bend specimen shows a highly tortuous crack. Secondary cracking is seen along with the main crack.

\section{DISCUSSION}

To explain the fracture behavior (stable or unstable) of the concrete specimens of different sizes and shapes, many researchers defined various brittleness numbers. Bazant and Pfeiffer [9] defined a brittleness number, $\beta$ as:

$$
\beta=B^{2} g_{f}\left(\alpha_{o}\right) \frac{f_{t}^{2} d}{G_{f} E_{c}}
$$

where $B$ is a constant which gives the plastic load capacity of the specimen calculated from $f_{t}$, $g_{f}\left(\alpha_{o}\right)$ is a nondimensional energy release rate equal to $\left\{k\left(\alpha_{o}\right)\right\}^{2}$ and $k\left(\alpha_{o}\right)$ can be obtained from the fracture mechanics handbooks [12]; $\alpha_{0}$ is the relative notch length, $G_{f}$ is the fracture energy, $E_{c}$ is the elastic modulus, $f_{t}$ is a strength parameter usually taken as direct tensile strength and $d$ is cross-section dimension of the specimen. The brittleness number, $\beta$, serves as an indicator of the type of fracture behavior. A specimen with a high brittleness number fails suddenly, with audible noise, and crack growth is unstable. A lower brittleness number is indicative of a material which demonstrates stable crack growth. We use the brittleness number to compare the observed fracture behavior of three- and four-point bend specimens of the same type of concrete. The ratio of two brittleness numbers for these different geometries can be calculated as:

$$
\frac{\beta_{3 p t}}{\beta_{4 p t}}=\left(\frac{B_{3 p t}}{B_{4 p t}}\right)^{2}\left(\frac{k\left(\alpha_{o}\right)_{3 p t}}{k\left(\alpha_{o}\right)_{4 p t}}\right)^{2}\left(\frac{\left(G_{f}\right)_{4 p t}}{\left(G_{f}\right)_{3 p t}}\right)
$$

where the ratios of fracture energy of concrete in two different loading conditions can be calculated from experimental load-CMOD plots shown earlier and the ratio of $k\left(\alpha_{o}\right)$ values is a geometry and load dependent quantity. Table 1 lists the results of the ratio of two brittleness numbers. If the material behaves more brittle in four-point bending than the three-point bending, its brittleness number will be higher and the ratio of the two brittleness numbers will be lower than 1 . Our calculated values suggest that for mortar specimens the four-point bend test is significantly less stable with respect to the three-point bend test. This is in agreement with our observation of catastrophic failure of mortar four-point bend test and stable crack growth in the three-point bend test. For normal and high strength concrete specimens the four-point bend test is less stable than the three-point bend test and stability of the four-point bend test improves if the upper roller distance is decreased. These analytical results are in good agreement with our experimental observations and similar to observations by Asghari and Barr [11]. 
Table 1: Ratio of brittleness numbers for three- and four-point bend tests

\begin{tabular}{|l|c|c|c|}
\hline & Mortar & $\begin{array}{c}\text { Normal Strength } \\
\text { Concrete }\end{array}$ & $\begin{array}{c}\text { High Strength } \\
\text { Concrete }\end{array}$ \\
\hline \hline $\mathrm{B}_{3 \mathrm{pt}} / \mathrm{B}_{4 \mathrm{pt}, 94^{*}}$ & 0.50 & 0.50 & 0.50 \\
\hline $\mathrm{k}\left(\alpha_{\mathrm{o}}\right)_{3 \mathrm{pt}} / \mathrm{k}\left(\alpha_{\mathrm{o}}\right)_{4 \mathrm{pt}, 94}{ }^{*}$ & 0.94 & 1.05 & 1.28 \\
\hline$\left(\mathrm{G}_{\mathrm{f}}\right)_{3 \mathrm{pt}} /\left(\mathrm{G}_{\mathrm{f}}\right)_{4 \mathrm{pt}}^{*}$ & 0.74 & 0.42 & 0.93 \\
\hline$\beta_{3 \mathrm{pt}} / \beta_{4 \mathrm{pt}, 94^{*}}$ & 0.30 & 0.66 & 0.44 \\
\hline \hline$\beta_{3 \mathrm{pt}} / \beta_{4 \mathrm{pt}, 15^{\dagger}}$ & - & 0.85 & - \\
\hline
\end{tabular}

* For the four-point bend test with inner span as $94 \mathrm{~mm}$

$\dagger$ For the four-point bend test with inner span as $15 \mathrm{~mm}\left(\mathrm{~B}\right.$ ratio $=0.92, \mathrm{k}\left(\alpha_{\mathrm{o}}\right)$ ratio $=0.98, \mathrm{G}_{\mathrm{f}}$ ratio $=0.96$ )

In the four-point bend geometry, a larger volume of the specimen is under uniform tensile stress compared to the three-point bend geometry (Figure 6). Microstructurally, this is manifested in greater damage or observed secondary cracking in the four-point bend specimens, and consequently toughening, as denoted by $\left(\mathrm{G}_{\mathrm{f}}\right)_{3 \mathrm{pt}} /\left(\mathrm{G}_{\mathrm{f}}\right)_{4 \mathrm{pt}}$ in Table 1 . The increase in toughness, however, does not translate into a relative decrease in brittleness with respect to three-point bending. Instead, we examine the energetics of the fracture process. Since the stored elastic energy in the four-point bend specimen is greater than in the three-point bend specimen, the elastic energy released during fracture of the four-point bend specimen is higher. If this released elastic energy is greater than that required to grow the crack and produce the attendant damage through the specimen, the crack will grow in an unstable manner and the specimen will fail catastrophically as observed in the case of the mortar specimens. If material absorbs the released energy by debonding the particles at the aggregate/matrix interface (NSC) or by fracturing the particles (HSC), the crack could grow unstably but later be arrested due to the presence of inclusions. When the upper roller distance in the fous-point bend test is reduced, crack stability improves, by limiting the size of the damage zone (and smaller magnitude of the stored elastic energy), as seen in Figure 1(c) for normal strength concrete specimen.

\section{SUMMARY}

1. The three-point bend specimens of the size studied here are found to exhibit stable crack growth in all three materials- mortar, normal strength concrete and high strength concrete.

2. The four-point bend specimens exhibit unstable crack growth. For mortar four-point bend specimens, fracture is calastrophic, whereas for normal and high strength concrete specimens fracture is quisi-catastrophic.

3. Reducing the distance between the upper rollers improves the stability of the fourpoint bend test.

4. Experimental observations of the load-CMOD relation agree very well with the results predicted by the brittleness number concept.

5. In four-point bend specimens a wider zone is subjected to high tensile stress, which causes more cracking in the specimen and makes crack growth unstable. 

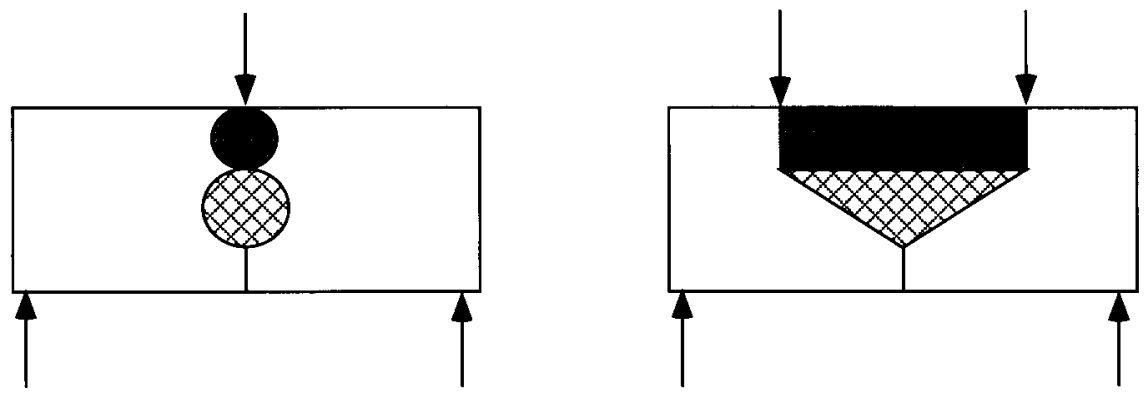

Figure 6: Regions of maximum stress in three- and four-point bend specimens.(dark: compression, cross-hatched: tension)

\section{REFERENCES}

(1) B.L. Karihaloo, A. Carpinteri, and M. Elices, Advn. Cem. Bas. Mat. 1(1), 92-105 (1993).

(2) S.P. Shah and C. Ouyang, J. Am. Ceram. Soc. 74(11), 2727-2738 (1991).

(3) S. Mindess, in Toughening Mechanisms in Quasi-Brittle Materials Edited by S.P. Shah, (Kluwer Academic Publishers, 1991) p. 271-286.

(4) L. Struble, P. Stutzman, and E.R. Fuller Jr., "Microstructural Aspects of the Fracture of Hardened Cement Paste," J. Am. Ceram. Soc., 72[12] 2295-2299 (1989).

(5) J.G.M. Van Mier, Toughening Mechanisms in Quasi-Brittle Materials Edited by S.P. Shah, (Kluwer Academic Publishers, 1991) p. 329-335.

(6) H. Horii, in Fracture Processes in Concrete, Rock and Ceramics Edited by J.G.M. Van Mier, J.G. Rots, and A. Bakkar, (E. \& F. N., 1991) p. 95-110.

(7) Z.P. Bazant and L. Cedolin, Stability of Structures: Elastic, Inelastic, Fracture and Damage Theories (Oxford University Press, 1991) p. 984.

(8) A. Carpinteri, J. Struct. Eng., 108(4), 833-848 (1982).

(9) Z.P. Bazant and P.A. Pfeiffer, ACI Mat. J., 1987, 463-480.

(10) Z.P. Bazant and R. Gettu, ACI Mat. J., 89(5), 456-468 (1992).

(11) A. Asghari and B. Barr, Fracture Processes in Concrete, Rock and Ceramics Edited by J.G.M. Van Mier, J.G. Rots, and A. Bakkar, (E. \& F. N., 1991) p. 515-522.

(12) H. Tada, P.C. Paris, and G.R. Irwin, The Stress Analysis of Cracks Handbook 1973.

\section{Acknowledgment}

This work was supported by the Center for Advanced Cement-Based Materials at Northwestern University. 